\title{
A Comparison of the Best Place to Fix Endotracheal Tubes for Men and Women When Men and Women Are in the Same Height
}

\author{
Shahram Nafisii ${ }^{*}$, Mehdi Rajabi², Mohammad Afshar ${ }^{3}$, Morteza Rashidian4, \\ Mitra Mohammadzadeh ${ }^{5}$ \\ ${ }^{1}$ Department of Anesthesiology, Advocate Illinois Masonic Medical Center, Chicago, IL, USA \\ ${ }^{2}$ Department of Anesthesia and Critical Care, Kashan University of Medical Sciences, Kashan, Iran \\ ${ }^{3}$ Faculty of Nursing and Midwifery, Kashan University of Medical Sciences, Kashan, Iran \\ ${ }^{4}$ Clinical Innovation Ins Trials, Costa Mesa, CA, USA \\ ${ }^{5}$ Shahid Beheshti University of Medical Sciences, Tehran, Iran \\ Email: ${ }^{*}$ nafisish@Yahoo.com
}

Received 25 May 2014; revised 25 June 2014; accepted 8 July 2014

Copyright (C) 2014 by authors and Scientific Research Publishing Inc.

This work is licensed under the Creative Commons Attribution International License (CC BY). http://creativecommons.org/licenses/by/4.0/

(c) (i) Open Access

\section{Abstract}

Background: Comparison of the tracheal tube depth over the same body height of men and women based upon intubation depth markings. Methods: Kashan University of Medical Sciences ethics committee approved the study and written informed consent was taken for each patient. Patients undergoing surgery requiring general anesthesia with oro-tracheal intubation were included in a prospective observational study. After induction of general anesthesia, the endotracheal tube was secured at the point at which the cuff was just below the vocal cord on laryngoscopy. Results: In a statistical study of 682 intubated patients which consisted of 499 women and 183 men, 28 cases of laryngoscopic view grade III and IV were excluded from the study. The measurement markings on the ETT at the level of right corner of the mouth were $20.65 \pm 0.13$ and $18.52 \pm 0.08$ for men and women respectively (CI 95\%). Patient's height has a meaningful correlation with the measurement of the fixation point of the ETT. Pearson correlation coefficient between the securing point of the tube and height was 0.2 and 0.357 for men and women respectively. In most cases of men and women of the same height, Mann-Whitney $U$ test rejected the hypothesis that the tube can be fixed in the particular point. Conclusions: In general, men are taller than women. Comparing the fixation depth of the tube, even when man and woman have the same body height, the endotracheal tube might be placed in a deeper level for men rather than women.

${ }^{*}$ Corresponding author.

How to cite this paper: Nafisi, S., Rajabi, M., Afshar, M., Rashidian, M. and Mohammadzadeh, M. (2014) A Comparison of the Best Place to Fix Endotracheal Tubes for Men and Women When Men and Women Are in the Same Height. Open Journal of Anesthesiology, 4, 153-158. http://dx.doi.org/10.4236/ojanes.2014.47021 


\section{Keywords}

\section{Intubation, Endotracheal Tube, General Anesthesia, Height, Cuffed}

\section{Introduction}

Unintentional endobronchial intubations are the most prevalent cause of oxyhemoglobin desaturation during an otherwise uneventful general anesthesia [1]. Various maneuvers have been used to prevent such a complication [2]. One common technique that has been proposed by Owen and Cheney is securing the orally placed endotracheal tubes (ETT) at the upper incisor teeth at the 23-cm mark in men and the 21-cm mark in women [3]. We have noticed that proper positioning of the ETT may be dependent on the height of the patient rather than the gender. This study was designed to compare the points of ETT fixation in men and women of the same height when the upper end of the ETT cuff is placed just below the vocal cords after tracheal intubation.

\section{Methods}

The study protocol was approved by the Ethics Committee of Kashan University of Medical Sciences, Kashan, Iran, and written informed consents were obtained from the patients.

A total 682 patients (183 were men and 499 were women) were included for the investigation which was performed between February 2004, and November 2008. These patients were scheduled to undergo the following surgical procedures: cesarean section, appendectomy, cholecystectomy, hysterectomy, hernia repairs, and other abdominal procedures. Exclusion criteria included; patients with a history of severe gastroesophageal reflux disease, those with anticipated difficult intubations, and edentulous patients. Patients with grade 3 and 4 laryngoscopic views were excluded from the study as well. Anesthesia was induced with either Sodium thiopental or Propofol. After mask ventilation was achieved, Succinylcholine, or a non-depolarizing neuromuscular blocking drug was administered. Assessment was made of the view at laryngoscopy, as described by Cormack and Lehane [4]. The classification was as follows: grade I = most of the glottis visible; grade II = only the posterior extremity of the glottis visible; grade III = no part of the glottis visible, only the epiglottis visible; grade IV = not even epiglottis visible. Laryngoscopic view of the patients was recorded. The trachea was intubated with a size 7 , 7.5, and 8 cuffed SUPA (SUPA C E, Tehran, Iran, PVC tracheal tubes, www.supamed.com) tracheal tube (Table 1). Direct laryngoscopy with MacIntosh 3 or 4 blades was performed by S.N. with the head and neck in sniffing position. After placement of the ETT's upper end of the cuff just below the vocal cords, a second operator inflated the cuff. The fixation point of the ETT at the right corner of the mouth was recorded.

Further confirmation of tracheal intubation was verified auscultation of bilateral breath sounds and symmetric chest expansion.

Patient data are presented as mean (SD). Spearman correlation and Pearson's correlation coefficients were used to determine relationship between patient's height and endotracheal tube fixation depth. The Mann-Whitney $U$ test was used to compare appropriate fixation depth of endotracheal tubes of men and women when they are the same height. Independent 2 sample student's $t$ test was used to check the hypothesis of equal mean depth fixation endotracheal tubes for men and women.

\section{Results}

The heights of the patients (Table 2) had a meaningful correlation with the measurement of the fixation point of the ETT. Pearson correlation coefficient between the depth of securing point of the tube and height was 0.2 and 0.357 for men and women respectively (Table 3). Table 4 also shows such a correlation. The mean length of the endotracheal tube tip to the fixation point at the right corner of the mouth when the cuff was just below the vocal cords was $20.65 \pm 0.13$ and $18.52 \pm 0.08$ for men and women respectively (CI 95\%) (Table 5).

Difficult intubations (the total of grade 3 and 4 laryngoscopic view as defined by Cormack and Lehane [4]) were most prevalent in cesarean cases. The lowest incidence of difficult intubations was in men. Incidence of difficult intubation was higher in cesareans (Table 6). Of the total 682 intubated patients which consisted of 499 women and 183 men, 28 cases of laryngoscopic view grade III and IV were excluded from the study (Table 7). 
Table 1. Criteria of SUPA endotracheal tubes (ETT).

\begin{tabular}{ccc}
\hline Internal diameter & Length from the beginning of the cuff to the tip $(\mathrm{cm})$ & Length from the end of the cuff to the tip $(\mathrm{cm})$ \\
\hline 7 & 6.5 & 2 \\
7.5 & 7 & 2.5 \\
8 & 7.5 & 2.5 \\
8.5 & 7.5 & 2.5 \\
\hline
\end{tabular}

Table 2. Patient height.

\begin{tabular}{cccc}
\hline & Average (mean) & Range & $95 \%$ CI \\
\hline Men & 173 & $160-188$ & $171-174$ \\
Women & 159.5 & $140-177$ & $159-160$ \\
\hline
\end{tabular}

Table 3. Correlation between patient's height and endotracheal tube fixation depth.

\begin{tabular}{ccc}
\hline & Parametric Pearson's correlation coefficient & Sig (p value) \\
\hline Men & 0.2 & 0.004 \\
Women & 0.357 & 000 \\
Men & and & Women \\
\hline
\end{tabular}

$\mathrm{p}<0.05$ considered significant.

Table 4. Correlation between patient's height and endotracheal tube fixation depth.

\begin{tabular}{ccc}
\hline & Nonparametric spearman correlation coefficient & Sig (p value) \\
\hline Men & 0.222 & 0.001 \\
Women & 0.343 & 000 \\
Men & 0.646 & 000 \\
\hline
\end{tabular}

$\mathrm{p}<0.05$ considered significant.

Table 5. Fixation depth of endotracheal tubes.

\begin{tabular}{ccc}
\hline & Range (centimeters) & Mean, $95 \%$ CI \\
\hline Men & $16.5-23$ & $20.65 \pm 0.13$ \\
Women & $16-21$ & $18.52 \pm 0.08$ \\
\hline
\end{tabular}

Table 6. Difficult intubation (grade 3 and 4 laryngoscopic view).

\begin{tabular}{cc}
\hline Woman (Cesarean Excluded) & $3.9 \%$ \\
\hline Men & $3.8 \%$ \\
Only Cesarean Cases & $4.3 \%$ \\
\hline
\end{tabular}

Table 7. Laryngoscopic view (Cormack classification).

\begin{tabular}{cccccc}
\hline & N & Grade I & Grade II & Grade III & Grade IV \\
\hline Woman & 499 & 307 & 171 & 21 & 0 \\
C/S & 346 & $207(59.8 \%)$ & $124(35.8 \%)$ & $15(4.3 \%)$ & 0 \\
Non C/S & 153 & $100(65.3 \%)$ & $47(30.7 \%)$ & $6(3.9 \%)$ & 0 \\
Man & 183 & $129(70.4 \%)$ & $47(25.6 \%)$ & $6(3.3 \%)$ & $1(0.54 \%)$ \\
Total & 682 & 436 & 218 & 27 & 1 \\
\hline
\end{tabular}


There was no accidental extubation or arterial desaturation.

Statistical analysis was performed using SPSS version 15 (SPSS inc., Chicago, IL).

Independent 2 sample student's $t$ test rejected the hypothesis of equal mean depth fixation endotracheal tubes for men and women. Mann-Whitney $U$ test in body height range of 160 - 173 centimeters rejected the hypothesis of the same point fixation of the ETT when man and woman are in the same height except when a man as tall as a woman was $173 \mathrm{~cm}$ or $164 \mathrm{~cm}$ (Table 8).

\section{Discussion}

An endotracheal tube cuff leak usually is obvious and is easily handled, while endobronchial intubation may be more difficult to find out, and can lead to hypoxemia secondary to collapse of the contralateral lung and hyperinflation of the intubated lung with resultant tension pneumothorax [2]. Asymmetric ventilation may be difficult to detect clinically and in most cases there is no change in capnography [5] [6]. In cases with grade 1 or 2 laryngoscopic views to prevent accidental bronchial intubation, we recommend to secure the endotracheal tube at the point at which the cuff is just below the vocal cords on laryngoscopy. This method of securing the endotracheal tubes is useful for patients in whom their head are in neutral or extended positions during the operation. It is not recommended in patients whose head may be flexed during operation.

Some anesthesiologists use the technique of Owen and Cheney [3] of routinely securing endotracheal tubes after orotracheal intubation when the 23- or 21-cm marks are at upper incisor teeth for adult men and women patients, respectively. This technique is also routine in our center. Therefore when a woman as tall as a man is intubated, the tube is secured at $21-\mathrm{cm}$ mark in the woman and $23-\mathrm{cm}$ mark in the man. It may result in subsequent migration of the cuff between the cords, especially for woman if she is tall. In reply to an editorial published in Anesthesiology [7], professor Cheney accepted it. Also in a man endobronchial intubation may happen, especially if he is short stature. Owen and Cheney did not explain how did they find 23- and 21-cm depth mark for positioning of the endotracheal tubes but they verified it by post-intubation radiography. However, their technique is useful for grade 3 and 4 laryngoscopic view, or in ICU, when frequent documentation of the tube position is necessary [7]. Cherng et al. [8] presented endobronchial intubation occurred in two female patient with body heights of $153-\mathrm{cm}$ and $155-\mathrm{cm}$ when endotracheal tube was positioned at 21-cm mark, but they did not mention that the measurement point was the upper incisor teeth or mouth angle. As far as endotracheal tubes are usually fixed in the right corner of the mouth, we consider the right corner of the mouth as the measurement point rather than the upper incisor teeth.

In this study, we have tried to match men and women regarding optimal tube placement when they were in the same body height. This comparison was possible in height range of $160-173 \mathrm{~cm}$ in which range that we had the same height men and women. We have found out that in most instances the optimal tube placement was

Table 8. Comparison of appropriate endotracheal tube length fixation.

\begin{tabular}{ccccc}
\hline Height & Result & Sig (p value) & Women (N) & Men (N) \\
\hline 173 & Accept & 0.282 & 3 & 11 \\
172 & REJECT & 0.002 & 8 & 27 \\
170 & REJECT & 000 & 17 & 4 \\
169 & REJECT & 0.008 & 8 & 10 \\
168 & REJECT & 0.014 & 12 & 6 \\
167 & REJECT & 0.002 & 18 & 4 \\
166 & REJECT & 0.003 & 11 & 14 \\
165 & REJECT & 000 & 34 & 4 \\
164 & Accept & 0.265 & 21 & 5 \\
163 & REJECT & 000 & 29 & 60 \\
\hline
\end{tabular}

$\mathrm{p}<0.05$ considered significant. 
deeper in men. The reason may be the length of different airway parts are less in female in comparison with the same height male. In our study, only in body heights of $164-\mathrm{cm}$ and $173-\mathrm{cm}$, optimal tube placement was exactly the same in men and women when the tube was fixed at the mouth angle. We found only one study [9] comparing a man with a woman of almost the same height in which the man's tracheal length was about 2 centimeter more than the woman and the tube was fixed deeper in the man.

Pearson correlation coefficient in my study shows that there is a positive correlation between height of the patient and depth of fixation of the ETT. Interestingly the correlation between a person's height and the length of his or her trachea is poor [9] [10], so bigger mouth, oropharynx, and laryngopharynx are the reasons of deeper fixation for the ETT in taller persons [10]. We have not found any study that men and women of the same height are matched for the proper endotracheal tube placement. In all references [11]-[13] the tracheal tubes were more deeply inserted in men because generally men are taller than women.

Tracheal length is less than 11 centimeters in many studies [10]. The length from the proximal part of an endotracheal tube cuff to the distal tip of our SUPA tubes is 7 - 7.5 centimeters (Table 1). Some authors believe that the tip of an endotracheal tube should be positioned close to the mid-point of the trachea [10], others state that endotracheal tube placement is considered adequate by placing the distal tip of the tube at least $3 \mathrm{~cm}$ above the carina [3]-[8].

If the endotracheal tube be secured at the point at which the cuff is just below the vocal cords on laryngoscopy, its tip has passed a few centimeters from the mid-point of the trachea. So we do not recommend a cuff-free sub-glotic laryngeal zone, and despite the view of Salem [5], when the tube cuff has been noted to be below the vocal cords on laryngoscopy, even in tall patients, we are not permitted to advance the endotracheal tube further, since it increases the probability of endobronchial intubation that is difficult to diagnose.

This study also compares the incidence of difficult intubation between obstetric group, non obstetric women and men (Table 6).

The power of this study is that during the period of about 5-year data gathering, all patients were intubated by the first author and the technique of intubation and recording of the intubation depth was exactly the same in all patients. Our goal was not to synthesize a formula for fixation of endotracheal tubes. We have tried to compare men and women when they are in the same body heights regarding tube placement and to recommend one more reasonable method of fixation of the endotracheal tubes. Keeping in mind that every patient must be judged individually and the presence of a vigilant anesthetist during intubation and securing the tube must not be ignored.

In conclusion, considering the tracheal length and the distance of the proximal part of the endotracheal tube cuff to its tip, tracheal tubes should be fixed at the point at which the cuff is just passed from the vocal cords.

\section{Shortcomings}

It was not feasible to provide chest X-ray, or fiberoptic bronchoscopy to check the space of the tube tip to carina of the patients.

In grade III and grade IV laryngoscopic view it was not possible to record the exact intubation depth marking when the tube cuff was just below the vocal cord so these patients were excluded from the study.

\section{Acknowledgements}

The authors thank Dr. Hossein Bovjari, Azad University, Kashan, Iran, for his valuable statistical analysis.

\section{References}

[1] Szekely, S.M., Webb, R.K., Williamson, J.A. and Russell, W.J. (1993) Problems Related to the Endotracheal Tube: An Analysis of 2000 Incident Reports. Anaesthesia and Intensive Care, 21, 611-616.

[2] Engoren, M. and de St. Victor, P. (2000) Tension Pneumothorax and Controlateral Presumed Pneumothorax from Endobronchial Intubation via Cricothyroidotomy. Chest, 118, 1833-1835. http://dx.doi.org/10.1378/chest.118.6.1833

[3] Owen, R.L. and Cheney, F.W. (1987) Endobronchial Intubation: A Preventable Complication. Anesthesiology, 67, 255257. http://dx.doi.org/10.1097/00000542-198708000-00019

[4] Cormack, R.S. and Lehane, J. (1984) Difficult Tracheal Intubation in Obstetrics. Anesthesia, 39, 1105-1111. http://dx.doi.org/10.1111/j.1365-2044.1984.tb08932.x

[5] Salem, M.R. (2001) Verification of Endotracheal Tube Position. Anesthesiology Clinics of North America, 19, 813-839. http://dx.doi.org/10.1016/S0889-8537(01)80012-2 
[6] McCoy, E.P., Russell, W.J. and Webb, R.K. (1997) Accidental Bronchial Intubation: An Analysis of AIMS Incident Reports from 1988 to 1994 Inclusive. Anaesthesia, 52, 24-31. http://dx.doi.org/10.1111/j.1365-2044.1997.007-az007.x

[7] Cheney, F.W. (1991) A Caution on the Use of Routine Depth of Insertion of Endotracheal Tubes: In Reply. Anesthesiology, 74, 962-963. http://dx.doi.org/10.1097/00000542-199105000-00042

[8] Cherng, C.-H., Wong, C.-S., Hsu, C.-H. and Ho, S.-T. (2002) Airway Length in Adults: Estimation of Optimal Endotracheal Tube Length for Orotracheal Intubation. Journal of Clinical Anesthesia, 14, 271-274. http://dx.doi.org/10.1016/S0952-8180(02)00355-0

[9] Chong, D.Y.C., Greenland, K.B., Tan, S.T., Irwin, M.G. and Hung, C.T. (2006) The Clinical Implication of the Vocal Cord-Carina Distance in Anaesthetized Chinese Adults during Orotracheal Intubation. British Journal of Anaesthesia, 97, 489-495. http://dx.doi.org/10.1093/bja/ael186

[10] Eagle, C.C.P. (1992) The Relationship between a Person's Height and Appropriate Endotracheal Tube Length. Anaesthesia and Intensive Care, 20, 156-160.

[11] Roberts, J.R., Spadafora, M. and Cone, D.C. (1995) Proper Depth Placement of oral Endotracheal Tubes in Adults Prior to Radiographic Confirmation. Academic Emergency Medicine, 2, 20-24. http://dx.doi.org/10.1111/j.1553-2712.1995.tb03073.x

[12] Reed, D.B. and Clinton, J.E. (1997) Proper Depth of Placement of Nasotracheal Tubes in Adults Prior to Radiographic Confirmation. Academic Emergency Medicine, 4, 1111-1114. http://dx.doi.org/10.1111/j.1553-2712.1997.tb03691.x

[13] Pollard, R.J. and Lobato, E.B. (1995) Endotracheal Tube Location Verified Reliably by Cuff Palpation. Anesthesia and Analgesia, 81, 135-138. 
Scientific Research Publishing (SCIRP) is one of the largest Open Access journal publishers. It is currently publishing more than 200 open access, online, peer-reviewed journals covering a wide range of academic disciplines. SCIRP serves the worldwide academic communities and contributes to the progress and application of science with its publication.

Other selected journals from SCIRP are listed as below. Submit your manuscript to us via either submit@scirp.org or Online Submission Portal.
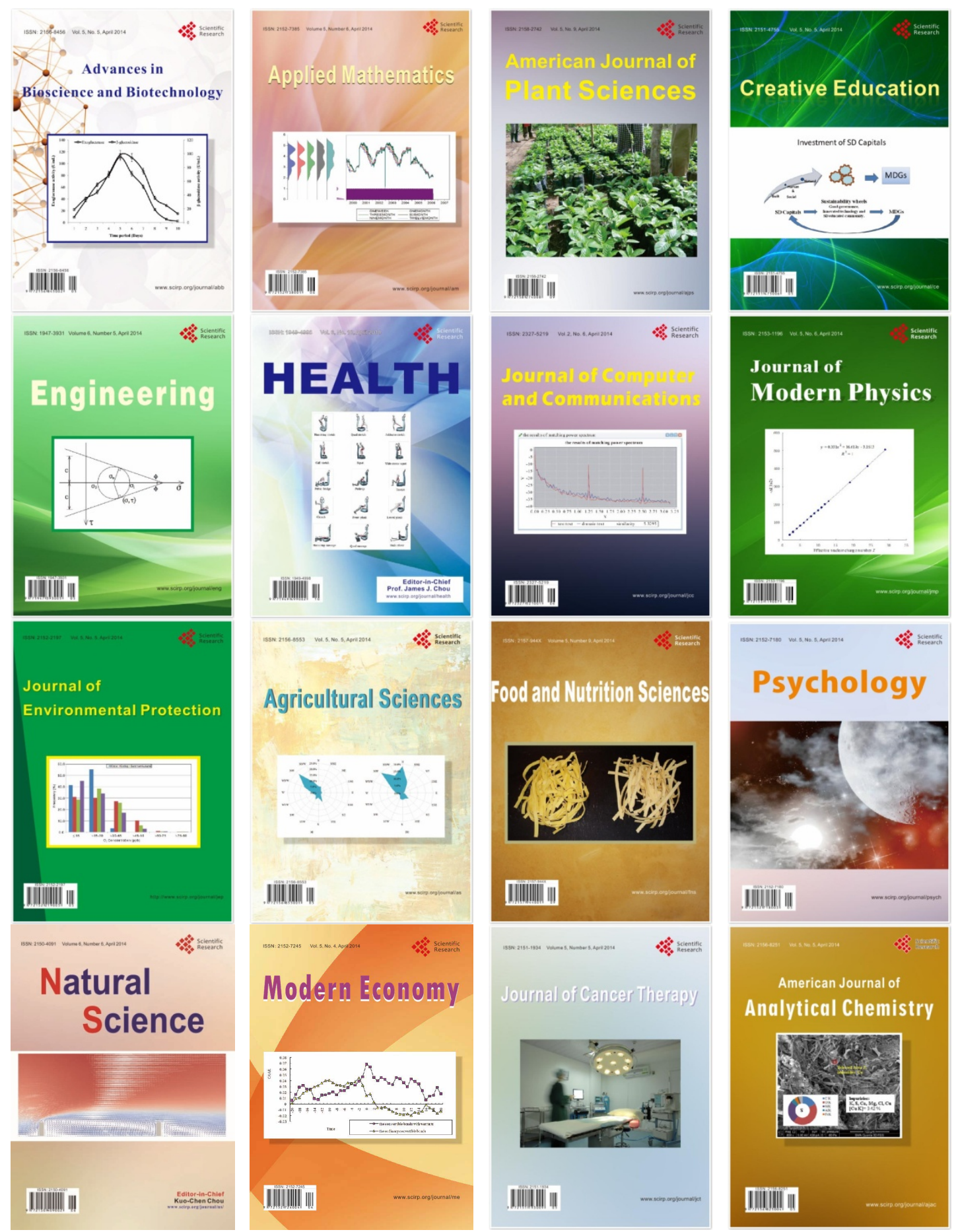